\title{
The European Journal of Health Law 1994-2019: How Innovative Has Its Contribution Been to the Development of Health Law in Europe?
}

With the last issue of the journal published in 2018, The European Journal of Health Law $(E J H L)$ completed its first 25 years of publication. This presents an appropriate moment to look back at the role of the journal in the field of health law. ${ }^{1}$ How innovative, for example, has its contribution been to the development of health law in Europe?

When the first issue was published in January of 1994, the aim and scope of the $E J H L$ was described as: 'The $E J H L$ focuses on the development of health law in Europe: national, comparative and international'. Although this has not changed over the years, I think it is important to emphasise that the Journal is not a Journal on European Health Law but the European Journal of Health Law.

In 1994 the EU had only 12 member states (whereas now there are 28); the Council of Europe consisted of 32 states, and now of 47 . Looking at the numbers in 1994, Professor Henk Leenen's initiative to start with the Journal in 1994 was, therefore not completely evident. Nevertheless, it is safe to say that from the beginning the very existence of the Journal has been an important innovative step in the development of health law in Europe. Of course, it is impossible to answer the question how health law in Europe would have developed had the Journal never seen the light of day, but there are still some quantitative and qualitative indications that give us an idea of the contribution of the Journal to the development of health law in Europe.

Let us first look at the quantitative indications. In order to do this, I examined the following types of articles:

- $\quad$ articles regarding one particular country ('national articles')

- $\quad$ articles regarding EU Law

- $\quad$ articles regarding Council of Europe Law

- $\quad$ articles on Comparative Law

- $\quad$ articles on International (Human Rights) Law

1 This editorial is based on the keynote lecture prepared for the 7 th Conference of the European Association of Health Law, held in Toulouse, France, from 25-27 of September 2019. Unfortunately, I was unable to present it there. 
In the first 5 years of publication, from 1994 to 1998, there were 54 articles that dealt with a single country:

United Kingdom

14

10

The Netherlands

Belgium, France, Germany, Norway, Sweden

3 each

Canada, Lithuania, Switzerland, usA

Austria, Denmark, Estonia, Finland, Italy, Poland and Portugal
2 each

1 each

Eighteen countries were covered in these articles. When we look at the five years following, from 1999 to 2003, we see a slight increase of these types of articles to 66 , with 22 countries covered:

Greece

8

The Netherlands, United Kingdom

7 each

Belgium, France

5 each

Spain, USA

4 each

Germany, Poland

3 each

2 each

1 each

From 2004 to 2008, we see a decrease again, with 54 articles covering 19 countries:

United Kingdom

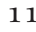

The Netherlands

10

Germany

7

Belgium

4

Ireland, Switzerland

3 each

Greece, Poland, Slovenia

2 each

Croatia, Denmark, Finland, France, Iceland, Israel, Lithuania, Russia,

1 each

Sweden, Turkey 
Then from 2009 to 2013 there were only 40 articles covering just 13 countries:

The Netherlands

United Kingdom

Denmark, Germany, Spain

Belgium, France, Ireland 3 each

Canada, Greece, Finland, Norway, Portugal 2 each 1 each

During the last 5 years (2014 to 2018), we see a further decline, with only 27 articles dealing with 14 single countries:

United Kingdom

Italy 4

France

Finland, Ireland, Sweden 2 each

Austria, Belgium, Denmark, Germany, Greece, Luxembourg, 1 each the Netherlands, Spain

On a map, the geographical distribution looks like this:

National Articles

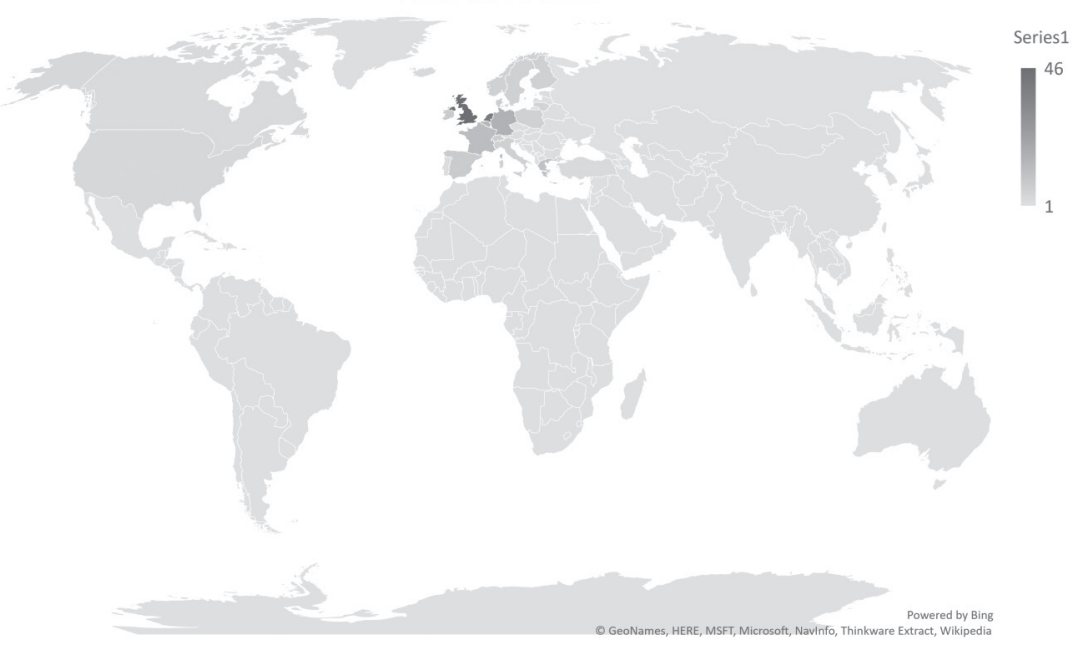


There has been a clear decrease of national articles over the years, with the highest number of articles (66) in the second five-year period, and the lowest (27) in the most recent one.

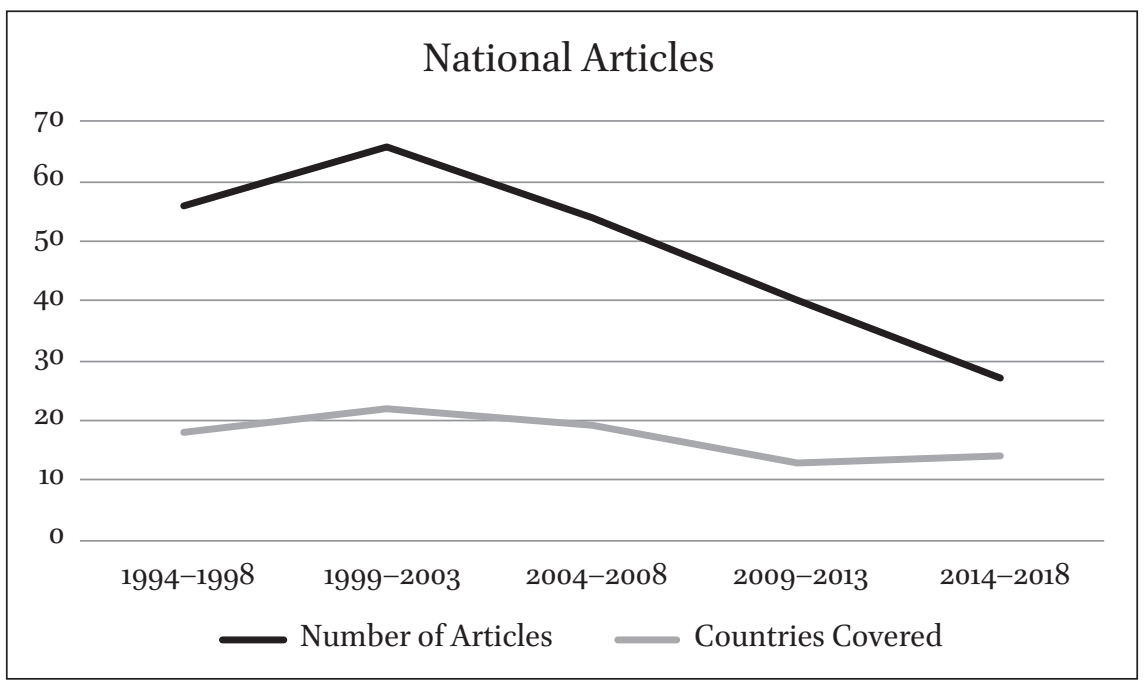

When we look at articles on EU law, we count a total of 79 articles with a sharp increase after 2012.

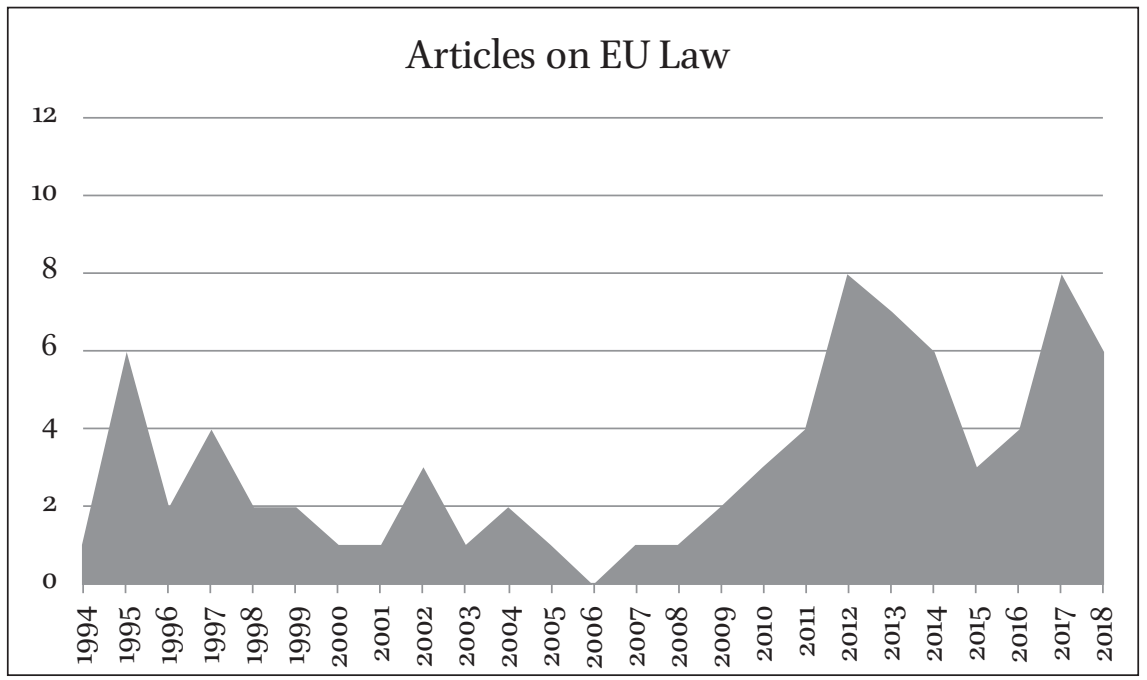


For articles on Council of Europe Law we see a very different trend:

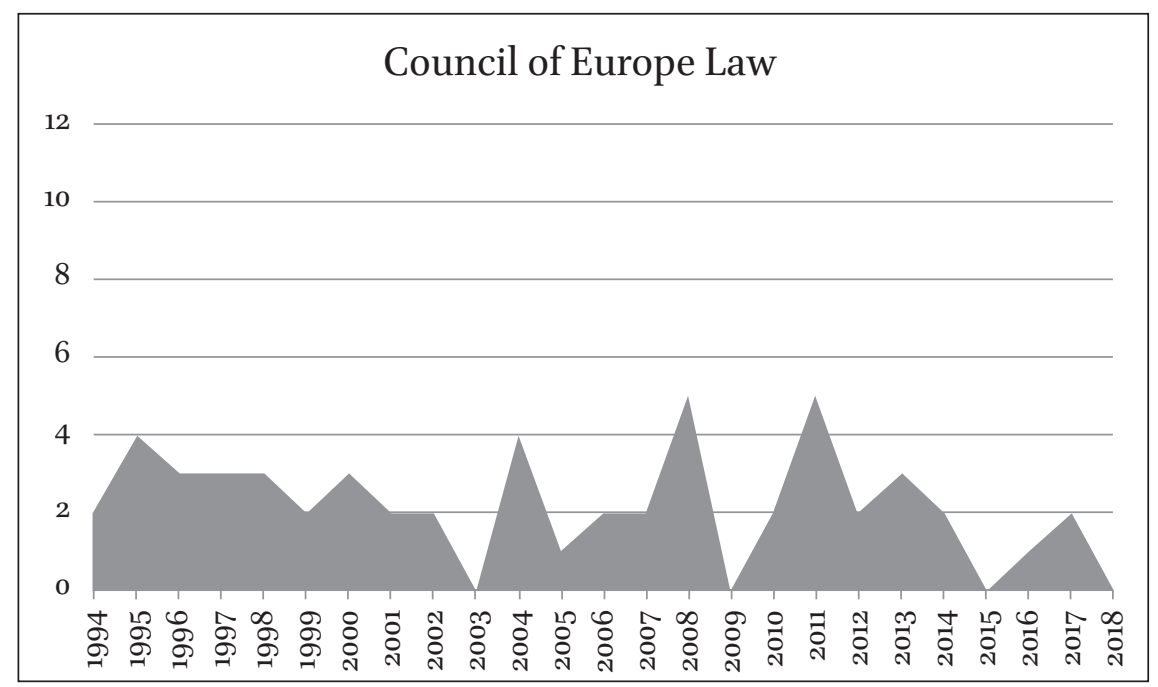

Here, we see a total of 55 articles, with a fairly stable number over the first 20 years, but showing a decrease since 2012:

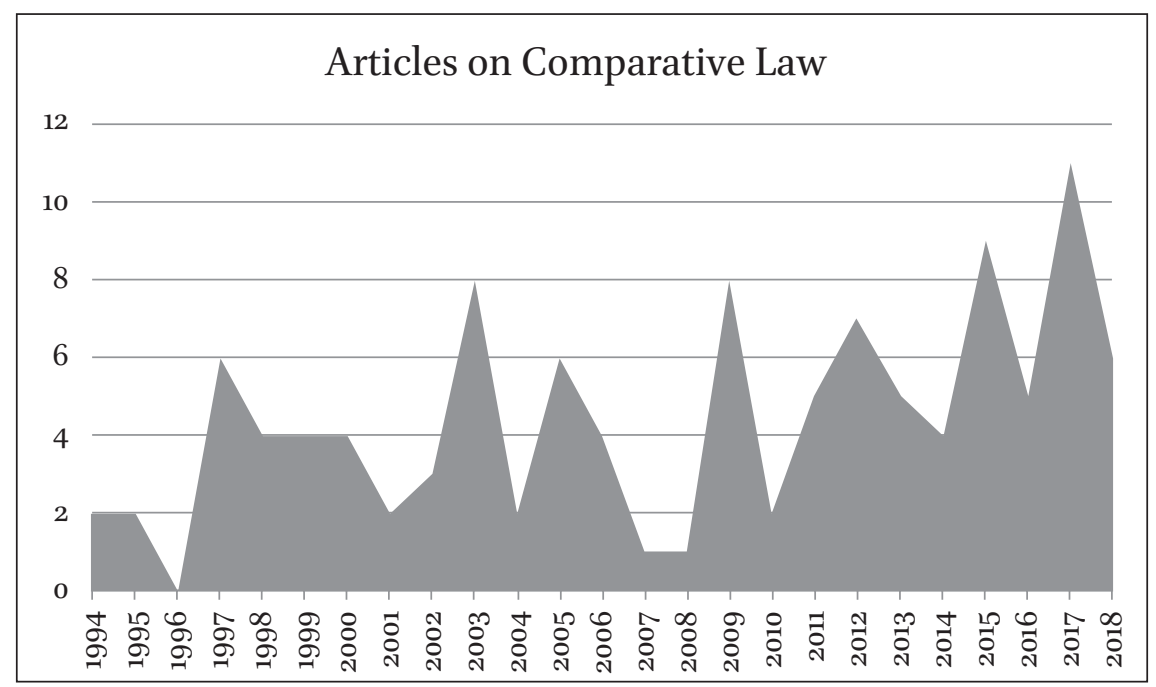


There were a total of 111 articles for comparative law, showing a stable distribution over the years and a slight increase in recent volumes.

For International (Human Rights) Law, there were 61 articles with a steady distribution over the years.

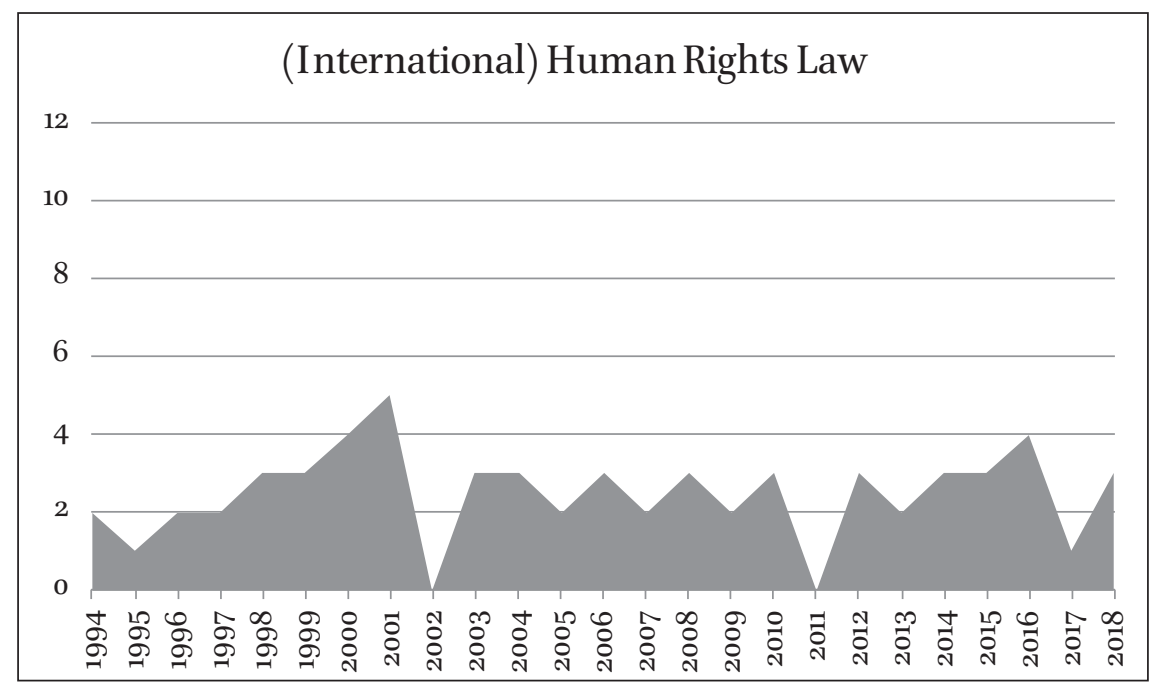

When we look at these all together, we see that articles on EU law and comparative law constitute the largest number of contributions. I believe that this development as well as that of the decreasing number of articles on national law, reflect the added value of the $E J H L$ for the development of health law in Europe.

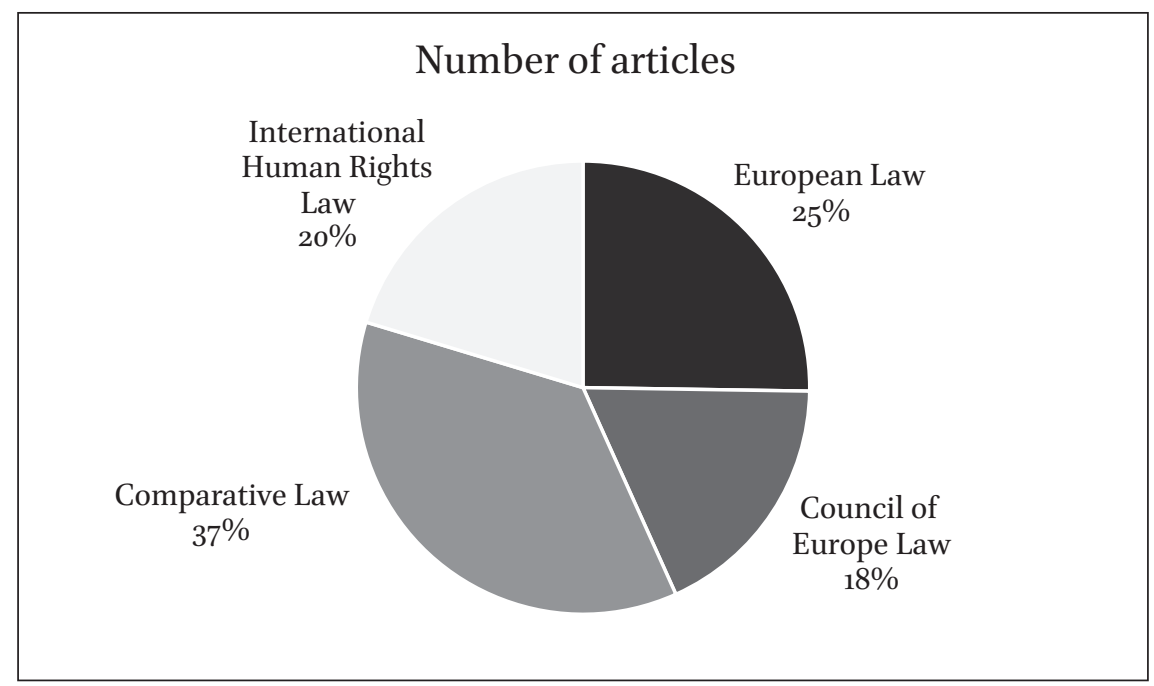




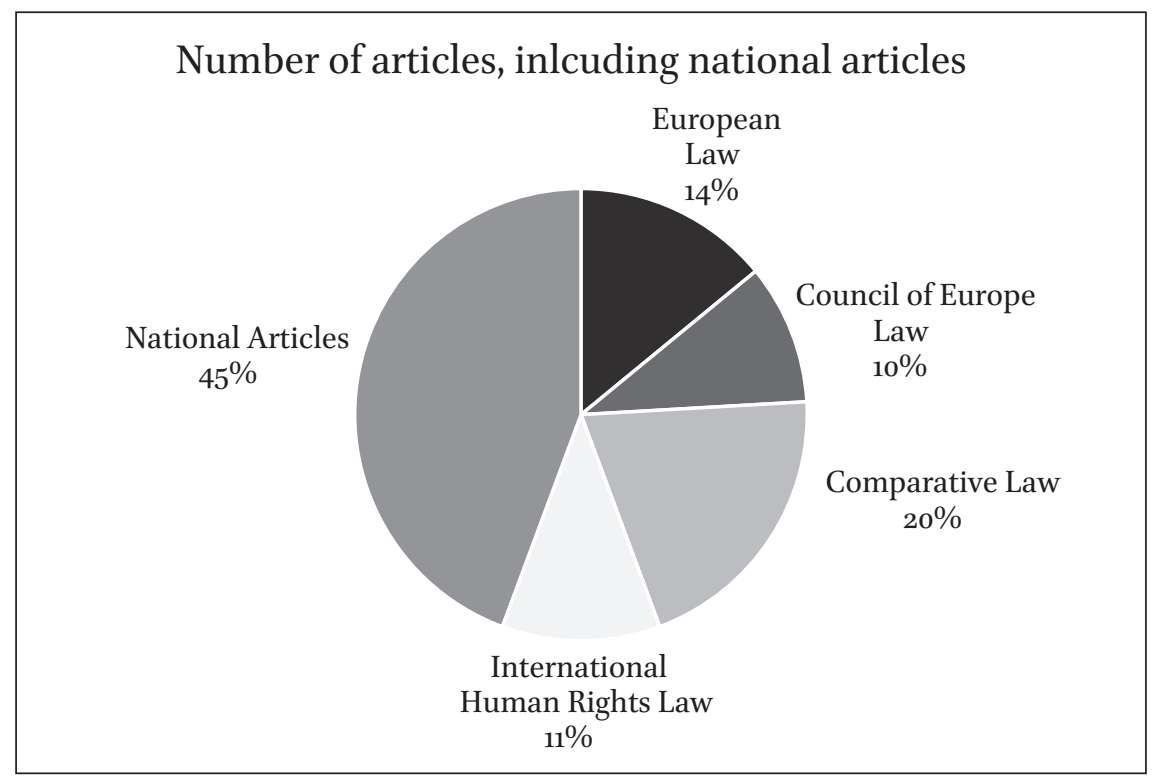

Let us now examine the qualitative indications, for which I have identified ten main themes:

1. Health law, separate discipline;

2. Beginning of life-embryo-abortion-artificial procreation;

3. Rights of patients (consent; information; quality and safety; representation; mentally ill)

4. Malpractice and compensation of damages (including wrongful birth and life);

5. Research with human subjects;

6. End of life: euthanasia, refusal of treatment, permanent vegetative state (PVs), advance directives (ADs);

7. Genes, tissue, organs, removal and transplantation, biobanks;

8. Professional law;

9. Organisation and provision of healthcare, health insurance, public health, cross-border care, pharma and devices;

10. Privacy, data protection, databases, secrecy, files. 
The distribution of articles on these 10 themes over the years are as follows below:

\begin{tabular}{|c|c|c|c|c|c|c|c|c|c|c|}
\hline & 1 & 2 & 3 & 4 & 5 & 6 & 7 & 8 & 9 & 10 \\
\hline 1994 & 4 & 3 & 8 & 1 & 3 & 2 & o & 2 & 0 & o \\
\hline 1995 & 2 & 1 & 5 & o & 1 & o & 7 & 5 & 3 & 1 \\
\hline 1996 & 0 & 1 & 6 & 3 & o & 3 & 2 & 4 & 4 & o \\
\hline 1997 & 1 & 4 & 4 & 1 & 1 & 7 & 1 & 4 & 1 & 1 \\
\hline 1998 & 1 & 0 & 7 & 1 & 1 & o & 3 & 1 & 6 & 2 \\
\hline 1999 & 1 & 1 & 5 & 1 & 3 & o & 2 & 2 & 7 & 2 \\
\hline 2000 & 1 & 1 & 6 & o & 2 & 2 & 7 & 1 & 3 & o \\
\hline 2001 & 1 & 1 & 6 & o & 2 & 6 & 3 & o & 3 & 2 \\
\hline 2002 & 1 & 2 & 5 & 2 & 1 & 3 & 2 & 2 & 1 & 5 \\
\hline 2003 & 0 & 1 & 7 & 5 & o & 3 & 1 & 2 & 2 & 2 \\
\hline 2004 & o & 3 & 6 & 2 & 3 & o & 4 & 1 & 3 & 3 \\
\hline 2005 & 1 & o & 2 & 4 & 1 & 8 & 1 & 2 & 2 & 1 \\
\hline 2006 & 6 & 1 & 5 & o & o & 3 & 2 & 1 & o & 2 \\
\hline 2007 & 2 & 2 & 6 & 2 & o & 3 & 2 & 3 & 1 & 1 \\
\hline 2008 & 6 & 2 & 2 & o & 10 & 1 & 3 & o & o & o \\
\hline 2009 & 1 & 1 & 2 & o & 1 & 5 & 4 & 3 & 2 & 2 \\
\hline 2010 & 6 & 1 & 4 & 1 & o & 1 & 6 & 3 & 5 & o \\
\hline 2011 & o & 4 & 10 & 1 & 1 & 3 & 3 & o & 3 & 3 \\
\hline 2012 & 1 & 3 & 8 & o & 1 & 4 & 2 & 1 & 4 & 2 \\
\hline 2013 & 1 & 4 & 2 & 1 & 3 & 2 & 3 & 2 & 4 & 3 \\
\hline 2014 & o & 1 & 11 & 2 & 3 & o & 1 & o & 2 & 4 \\
\hline 2015 & 1 & 4 & 1 & 2 & o & 2 & 4 & 3 & 3 & o \\
\hline 2016 & 2 & 1 & 2 & 1 & 3 & 1 & 1 & 2 & 5 & 4 \\
\hline 2017 & 1 & 2 & 2 & 2 & 2 & 2 & 4 & 1 & 7 & 2 \\
\hline 2018 & 1 & 2 & 1 & 2 & o & 3 & 5 & 2 & 6 & 5 \\
\hline Total & 41 & 46 & 123 & 34 & 42 & 64 & 73 & 47 & 77 & 47 \\
\hline
\end{tabular}


We have also looked at the articles, divided by theme:

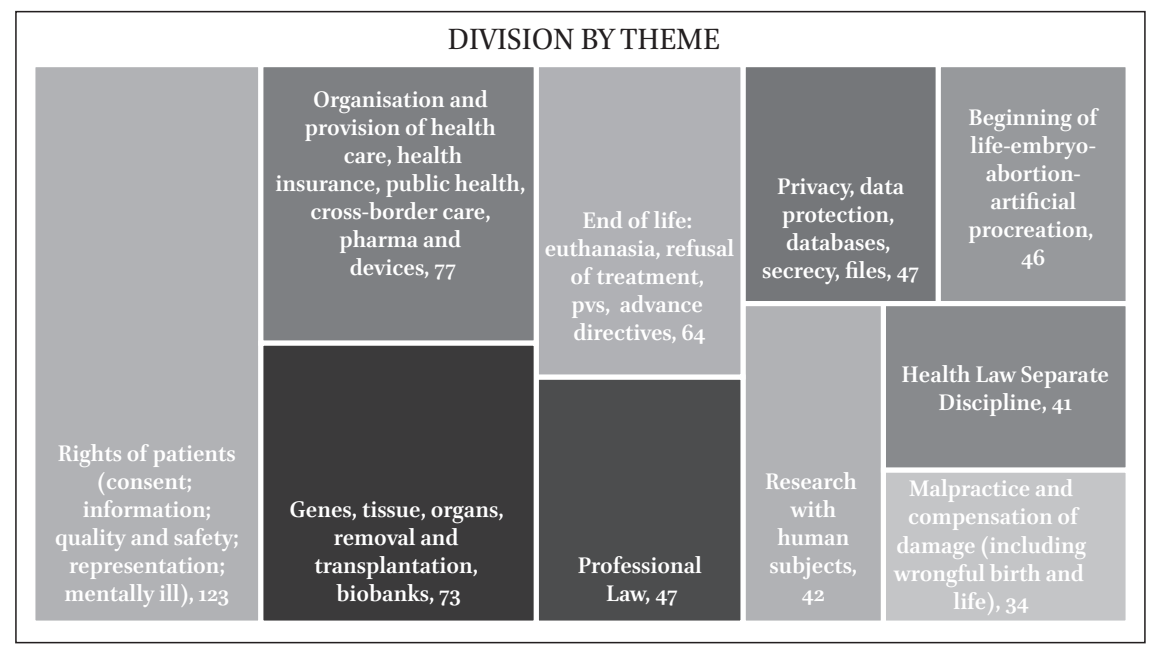

When we look at all these figures. we can conclude that the European Journal of Health Law covers all of the important health law topics. Almost half (280) of all (594) articles deal with the rights of the patient in the broader sense: right of patients, beginning and end-of-life, and data protection. We also see that ethically sensitive issues such as scientific research, use of human material, removal and transplantation of organs are also well-covered in the Journal. The more classic themes such as professional law and malpractice are also present at a stable but rather low level. Most of all, these trends indicate that the Journal is contributing to a dynamic and innovative development of health law in Europe.

At the end of this overview of the contribution of the Journal to the development of health law, I would like to thank our colleague Jos Dute who has been an editor of the $E J H L$ for almost fifteen years, and has now decided to withdraw from the board. Jos' contribution to the Journal has been impressive, especially because of his summaries of the judgments of the European Court of Human Rights that are relevant for health law, but also in other respects, such as editorials and reviewing special issues. On behalf of all the readers of the Journal, my co-editors, the members of the editorial board, and our publisher I want to thank Jos cordially for his contribution to the Journal over the years, and to wish him all the very best in the future. 
European Journal of Health Law, Editors 1994-2019

1994 Founding Editors: Sjef Gevers and Henriette Roscam Abbing

2005 Jos Dute

2010 Herman Nys

2011 Sjef Gevers steps back.

2019 Titti Mattson; Jos Dute steps back.

\section{Herman Nys}

Editor-in-Chief, European Journal of Health Law; Professor Emeritus of Health Law, KU Leuven, Leuven; First Vice Chair, European Group on Ethics in Science and New Technologies, European Commission, Brussels, Belgium 